\title{
Geradores sensíveis, relações interpessoais e democracia: experiências de cinema com adolescentes no sistema socioeducativo
}

\section{Sensitive generators, interpersonal relations and democracy: film experiences with teenagers at Brazilian socio-educational system}

\author{
Júlio FIGUEROA ${ }^{1}$ \\ Luciana OLIVEIRA ${ }^{2}$
}

\begin{abstract}
Resumo
No artigo apresentamos um experimento de pesquisa empírica que coloca em relação cinema e educação no contexto de adolescentes que, de diferentes formas, estão no sistema socioeducativo brasileiro. A partir de uma visada construtivista da política como lócus do dissensual e da invenção da igualdade bem como da reivindicação ao direito da imagem de povos e pessoas subalternizados, a pesquisa buscou constituir um espaço dialógico em torno da exibição de filmes não-convencionais, avessos às formas mais codificadas da cultura massiva. Em face disso, interrogamos de que modo o aparato sensível do cinema pode abrir espaço dialógico para a expressão de si dos adolescentes a transformação do silêncio em linguagem - imaginando que modos de subjetivação e interação mais abertos e autônomos são premissas de suma importância para a experiência democrática.
\end{abstract}

Palavras-chave: Cinema; Educação; Sistema Socioeducativo; Democracia.

\begin{abstract}
In the article, we present an empirical research experiment that puts in relation cinema and education in the context of adolescents who, in different ways, are in the Brazilian socio-educational system. From a constructivist view of politics as the locus of dissent and the invention of equality as well as the claim to the right of the image of subaltern peoples and persons, the research sought to establish a dialogical space around the exhibition of unconventional films, averse to huge codified forms of mass culture. In the face of it, we ask how the sensitive artifact of cinema can open dialogic space for adolescents' self-expression - the transformation of silence into language - imagining

\footnotetext{
${ }^{1}$ Graduado em Comunicação Social pela Universidade Federal do Ceará. Mestre em Comunicação e Cultura Contemporâneas pela Universidade Federal da Bahia. Doutorando em Comunicação Social pela Universidade Federal de Minas Gerais. E-mail: juliovfigueroaa@gmail.com

2 Professora do Departamento de Comunicação Social e do Programa de Pós-graduação em Comunicação Social da Universidade Federal de Minas Gerais. E-mail: luciana.lucyoli@gmail.com
} 
that more open modes of subjectivation and interaction are premises what plays a central political role to the democratic experience.

Keywords: Cinema; Education; Socio-Educational System; Democracy.

\section{Introdução}

Ao lado de Rancière (1996, p. 36) estamos quando ele afirma que

Há política porque o logos nunca é apenas a palavra, porque ele é sempre indissoluvelmente a contagem que é feita dessa palavra: a contagem pela qual uma emissão sonora é ouvida como palavra, apta a enunciar o justo, enquanto uma outra é apenas percebida como barulho que designa prazer ou dor, consentimento ou revolta.

É sabido que há fatores que facilitam a entrada de adolescentes na criminalidade, atuando decisivamente para isso a miséria, o afastamento da escola e o racismo $^{3}$. Tais adolescentes, em geral, não têm considerados seus sons emitidos ou, se considerados, são escutados como ruídos, já que exprimem algo descartável, que não porta nenhum significado relevante ou visão de mundo que possa contribuir para a melhor convivência em sociedade. Ora, Rancière não convida a entrada das pessoas ditas ruidosas pela porta da casa ou mesmo por outra via simples; convida, sim, a pensar, antes de uma reunião na residência, a própria decisão por fazer a reunião e as regras de comunicação que serão adotadas nela, assim como convida a colocar em questão a própria casa como espaço mais ou menos adequado para o encontro.

\footnotetext{
${ }^{3}$ De acordo com o relatório do Sistema Nacional de Atendimento do Sistema Socioeducativo (Sinase), os números de 2016 mostram um total de 26.450 atendidos, sendo 18.567 em medida de internação (70\%), 2.178 em regime de semiliberdade (8\%) e 5.184 em internação provisória (20\%). O relatório também traça um perfil etário de adolescentes em conflito com a lei: a maior proporção dos adolescentes está concentrada na faixa etária entre 16 e 17 anos com 57\% (15.119), seguida pela faixa etária de 18 a 21 anos com 23\% (6.728), entre 14 a 15 anos com 17\% (4.074) e 12 a 13 anos com 2\% (326), havendo, ainda, $1 \%$ sem especificação de faixa etária (203).

Ainda de acordo com esse relatório, 59,08\% são negros. Disponível em: <https://bit.ly/33xUqcM>. Acesso em: 28 set. 2019.

Já a pesquisa IPEA (2015) mostra que 66\% vivem em famílias extremamente pobres, 60\% são negros, $51 \%$ não frequentavam a escola quando cometeram o delito. Disponível em: 〈https://bit.ly/2Ozk8JG〉. Acesso em: 28 ago. 2015.
} 
Se, no mundo de ruas, centros e periferias, adolescentes ruidosos já estão fora dos tabuleiros e das escolhas dos tabuleiros e dos jogos que compõem as decisões "policiais", nos termos de Rancière, é de se supor que elas continuem caminhando por trilhas alheias quando estão em centros socioeducativos, nos quais a coerção quase sempre está acima do propósito de "socioeducar"4 Polícia e política, para Rancière, são duas maneiras de contar quem faz parte de uma comunidade. "A primeira só conta partes consideradas reais, grupos institucionalizados ou definidos por diferenças de nascimento, de funções, de lugares e de interesses que constituem o corpo social, e exclui o resto, os sem parte na comunidade. A segunda conta a mais uma parte dos "sem-parte", escreve Rancière (2014, p. 146). A questão política refere-se à verificação da igualdade pressuposta pela polícia e à manifestação do "incontado"; ou seja, à aparição daquilo que a ordem faz desaparecer: a diferença que reside no interior da igualdade presumida, mundos que não contam, mas que existem dentro do mundo dos que contam. Trata-se de uma reconfiguração do comum, de um rearranjo da medida do comum. $\mathrm{O}$ desafio colocado pelo filósofo está em optar por outra lógica, que, pela "atualização da contingência da igualdade dos seres falantes quaisquer", suspende a falsa harmonia dos corpos no espaço que os apresenta ou que os omite, tornando-os visíveis ou invisibilizando-os (RANCIÈRE, 1996, p.40-41).

Didi-Huberman (2011a, p. 52), acompanhando Arendt, sugere, no texto “Coisa pública, coisa dos povos, coisa plural”, um fazer artístico específico, em nome de, poderia ser dito, um projeto, em que possam ser expostos os povos que estão sem direito à imagem em determinada matriz: em sua multiplicidade, facilidade e diferenças reunidas por intervalos em rede. As reflexões aqui presentes vão ao encontro desse movimento, buscando identificar faíscas de resistência imagética e corporal capazes de compor outras e novas histórias, formas de ver e ser visto, formas de interagir e manter essa interação,

\footnotetext{
${ }^{4}$ Em algumas unidades, a energia está mais na coerção do que na socialização, como observam Menicucci e Carneiro (2011, p. 553).
} 


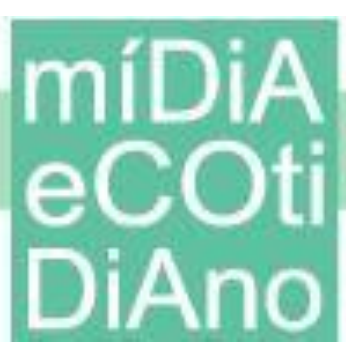

capazes de tornar expressáveis as inferiorizações e distanciar-se das intenções e práticas de fazê-las invisíveis.

Não se pode negar que há certa semelhança entre um acontecimento real e o modo como se apresenta uma cena cinematográfica. A cena trabalha bastante para ser isso, em certo sentido ${ }^{5}$. Tão bem sucedida foi essa tarefa que o cinema mais consumido insiste em programar efeitos, copiando modos de associação entre imagens e sons que juntos sugerem a cobertura de um dado evento como se este estivesse sendo observado em sua presença de fato: "a experiência de assistir o filme é significada pela mente como se fosse o próprio ato de estar atuando psicomotoramente.” (BALÁZS, 1983, p. 85). Uma pergunta que não se pode segurar e que surge da desconfiança é a de que conjuntos de imagens mais reprodutores e menos criadores estão trazendo, senão mais distância entre indivíduos, mais burocracia para o que se dá a ver. Haveria uma espécie de membrana imagético-midiática que interpela o olhar de um para o outro.

No Brasil, cerca de 28 mil adolescentes que têm entre 12 e 18 anos incompletos cumprem medidas socioeducativas em unidades de internação ${ }^{6}: 30 \%$ destes centros cumprem o que prevê o Estatuto da Criança e do Adolescente, o que inclui a devida escolarização que devem receber. Isto torna urgente a necessidade de manutenção e evolução de um debate propositivo e também voltado à ação, especialmente considerando iniciativas truculentas de mudança das regras do sistema, dentre as quais a proposta de alteração da idade penal de 18 para 16 anos.

Este artigo é parte de uma pesquisa ${ }^{7}$ que deseja elaborar ações para mover, em adolescentes cumprindo medidas no sistema socioeducativo (seja em regime de liberdade assistida ou privação de liberdade), percursos outros de sua dimensão sensível, ativados a partir de apreciação de obras, rodas de conversas e exercícios audiovisuais. Aqui, buscamos experimentar formas de socioeducar com cinema, guiados pela noção

\footnotetext{
5 Hugo Munsterberg, no início do século XX, já enfatizava o esforço do cinema na reprodução de mecanismos da mente, tais como a atenção, a memória, a imaginação e a emoção, afirma Andrew (2002, p. 29).

${ }^{6}$ CNJ. Panorama Nacional - A Execução das Medidas Socioeducativas de Internação. Conselho nacional de Justiça. 2011.

${ }^{7}$ Investigação do Doutorado em Comunicação Social da Universidade Federal de Minas Gerais. O estudo agora parte para a segunda pesquisa de campo em 2020 com jovens que entraram no sistema socioeducativo na cidade de Fortaleza.
} 
dialógica de educação de Paulo Freire (2003; 2008), de modo a compreender o recorte do sensível de jovens que caíram na malha do sistema judicial. Afinal, como nos lembra o educador brasileiro: "falar em democracia e silenciar o povo é uma farsa" (FREIRE, 2003, p.96). Nossa hipótese principal é a de que tais espaços de igualdade agenciados por temas geradores sob a forma de filmes podem fazer frente a uma lógica de adestramento ou de ensino bancário inerente à noção de correção, a que o Sistema Nacional de Atendimento Socioeducativo (SINASE) se refere como responsabilização.

Os estudos que se dedicam à relação entre cinema e educação sensível na adolescência têm como espaço de maior atuação o ambiente escolar. Apesar de algumas experiências em presídios e hospitais, como as realizadas por iniciativa de Migliorin (2015, p. 166) e Fresquet (2013, p. 117), a ênfase principal sempre está no cinema dentro da escola, disso decorrendo todo o arsenal prático e teórico. Esta pesquisa pretende fazer avançar os estudos junto a jovens em conflito com a lei - ou seria a lei em conflito com os jovens? -, aproximando ainda cinema e vulnerabilidade social.

\section{Para um tratamento cinematográfico do visível: cinema-educação}

Nossa perspectiva também está em sintonia com o esforço de desconstruir a concepção instrumentalizada do cinema na prática pedagógica - Bergala (2008, p. 3334), Fresquet (2013, p. 60-61) e Migliorin (2015, p. 28). Esse movimento procura ir ao encontro da seguinte afirmação: “a educação na prisão não é apenas ensino, mesmo que devamos ter certeza de que a aprendizagem de conhecimentos básicos esteja assegurada. (...) a educação deve ser, sobretudo: desconstrução/reconstrução de ações e comportamentos" (MAEYER apud JULIÃO, 2010, p.11). Na apreciação dos filmes, resgatamos a atitude de não partir das ideias, mas partir das experiências dos participantes, de suas travessias pessoais frente ao filme (BERGALA apud FRESQUET, 2013, p.49), o que é de grande auxílio no trabalho dentro da sala de aula em uma unidade de internação, pois retira as ideias de dentro da reflexão pura e as engendra no fluxo dos acontecimentos vividos e comentados.

Nossa proposta de pedagogia cinematográfica, pedagogia da incompletude possível, não busca condução alguma, seja por coerção, seja por sedução. Ao pensá-las, há a clara despretensão de oferecer um caminho. As propostas buscam ultrapassar a 
instituição, aproximando-se de um determinado sentido de comum: "comum é tudo aquilo que nos oferece os recursos de uma livre busca de uma identificação que não está dada, que não está constituída" (SILVA, 2011, p. 20). Existe porosidade total àquilo que virá, que não foi planejado. Isso não significa aprovação incontestável, mas diz que não há tabu e ferramentas prévias para tosar o desenrolar das conversas.

Fazendo agir a pedagogia crítica, entendemos que essa noção de comum pode impulsionar, no encontro entre universidade pública e centros socioeducativos, motivações mais desobedientes em direção à busca de um comum. A proposta, portanto, não busca fazer coincidir aquilo em que ela acredita com aquilo que adolescentes devem acreditar. Devemos, nesse sentido, evitar ter como objetivo a equivalência entre o suposto nível de excelência do detentor de saber e o nível de saber que o aprendiz deve alcançar. Cabe mantermos distância da

lógica do pedagogo embrutecedor, a lógica da transmissão direta e fiel: há alguma coisa, um saber, uma capacidade, uma energia que está de um lado - num corpo ou numa mente - e deve passar para o outro. $\mathrm{O}$ que o aluno deve aprender é aquilo que o mestre ofaz aprender. O que o espectador deve ver é aquilo que o diretor ofazver. O que aquele deve sentir é a energia que este lhe comunica. A esta identidade de causa e efeito que está no cerne da lógica embrutecedora, a emancipação opõe sua dissociação (RANCIÈRE, 2002, p.18).

Essa espécie de recomendação é válida tanto para a prática pedagógica entre mestre e aluno, tal como costumeiramente compreendida, como para pensar sobre o contato de um espectador com um filme. Há para nós, contudo, uma intenção fundante, que é a de promover a criação de um comum cuja identificação não está construída, mas é produzida a partir das demandas sensíveis de adolescentes, considerando a condição individual em que se encontram e a instituição onde estão. Os exercícios cinematográficos que propomos compõem, nesse sentido, campos e inclinações para fazer viverem, como identificou Didi-Huberman (2011, p. 72) simultaneamente em Pasolini e Agamben, as

linguagens do povo, gestos, rostos: tudo isso que a história não consegue exprimir nos simples termos da evolução ou da obsolescência. Tudo isso que, por contraste, desenha zonas ou redes de sobrevivências [grifos do autor] lugar mesmo onde se declaram sua 
extraterritorialidade, sua marginalização, sua resistência, sua vocação para a revolta.

É possível desfrutar do direito de estar cognitivamente e sensivelmente desacostumado ou inadequadamente habituado para, por meio de vias antes ignoradas ou diminuídas, prover de expressão, nos passos de Migliorin (2015, p. 51), tanto as cores e formas quanto os ritmos de movimentação de outras pessoas e de si mesmo, assim como de objetos e mobílias dispostos no ambiente. Mas esta nova “equipagem" sensível traria de benéfico o quê propriamente? Fresquet (2013, p. 19) insinua uma resposta: "uma nova forma de membrana para permear um outro modo de comunicação com o outro (com a alteridade do mundo, das pessoas, das coisas, dos sistemas) e com o si próprio".

Vemos íntima aproximação dessas reflexões para interação presencial na seguinte afirmação:

A atividade política é aquela que desloca um corpo do lugar que lhe era designado ou muda a destinação de um lugar; ela faz ver o que não cabia ser visto, faz ouvir um discurso ali onde só tinha lugar o barulho, faz ouvir como discurso o que só era ouvido como barulho (RANCIÈRE, 1996, p. 42).

O corpo do indivíduo pode ser recriado, imaginado, pensado e transformado na medida em que ele é também, na concretude dos dias, exercício cinematográfico de escuta e visão atentas, de realocação de recursos dramatúrgicos, significados e sugestões de invenção que, longe de estarem predeterminadas, podem existir mais livremente a partir de conexões inéditas ou reinserções atípicas. Vemos muitas afinidades entre essa visão filosófica e a visão filosófico-prática de Paulo Freire $(2003 ; 2008)^{8}$, de quem em muito nos nutrimos para a composição empírica dos encontros com cinema. Para pensar a concretização dos encontros e das trocas de saberes como gesto interacional, retomamos a noção de diálogo do educador para quem produzir conhecimento é produzir relação. Segundo ele, a educação problematizadora é dialógica — não "bancária" ou pensada como um depósito do conhecimento - que, como exigência existencial propõe o encontro mediatizado pelo mundo para co-criar a pronúncia. É o encontro entre agências

\footnotetext{
${ }^{8}$ Uma pesquisa de Lewis (2012) faz um importante inventário dessas afinidades para pensar a relação entre educação e estética de forma mais geral e, de forma particular, entre educação e teatro.
} 


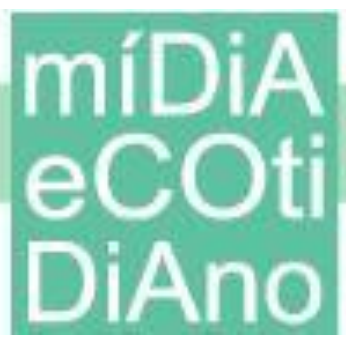

que pronunciam o mundo que, como ato de criação, não pode ser "doado" ou transmitido de uma pessoa a outra. Assim a educação é um processo de troca de saberes que pressupõe que a pessoa que está diante de quem ensina é sábia e que ensinar é aprender, encontrar - com outras pessoas, com o professor - é fazer dizer o que se sabe. Inspirada em Freire, bell hooks (2013) associa diálogo com o que chama de comunidade pedagógica, calcada numa solidariedade transfronteiriça que possa emergir para além de cristalizações sobre o outro, bem como dos diferentes lugares de poder e fala, consolidando alianças possíveis a partir de existências radicalmente diferentes que se colocam a experimentar e construir um comum.

As atividades de escolha, disposição e ataque, feitas durante a realização de um filme e propostas por Bergala (2008, p. 135), por exemplo, sublinham movimentos éticos que contemplam concepções de mundo e de atuação nesse mundo. As três categorias especificadas, que correspondem a colocar em diálogo decisões dramatúrgicas, espaciais, plásticas e rítmicas, dizem diretamente do mundo que se apanha e ao mesmo tempo se deixa escapar, do mundo que se vê e que se deseja. Expor essa engenharia aberta em movimento é também lançar questões sobre o estar de si no mundo. Ao mesmo tempo, evitar essa inclusão expressiva é ignorar um potencial repertório que, embora construído sob a dimensão do visível, é invisibilizado, pertencente ao universo do barulho, do cinismo naturalizado em silêncio incômodo, que sobrevaloriza ao mesmo tempo que faz inexistir. Pessoas e expressões, por drástica afinidade, se encontram no mais profundo escuro, onde não é possível ver nada nem ninguém.

Como já anunciado, pensar a imagem para além da tela inclui considerar fortemente as conexões entre o olhar componente do corpo e o corpo que é, ao mesmo tempo, alvo do olhar. É inegável que tomamos inspirações que estão inscritas na compreensão do cinema como linguagem, articuladora, mas não apenas isso, de códigos de olho e ouvido. Seja por omissões, ênfases, supressões, contrastes e continuidades construídas com elementos visuais internos a um plano ou que se evidenciam no contato com o que o antecede ou o precede, a construção de significado pode ser aliada de formas de lidar com a exterioridade presencial, mas não deveriam agir, tal como compreendemos, como bússola perceptiva matriz. 


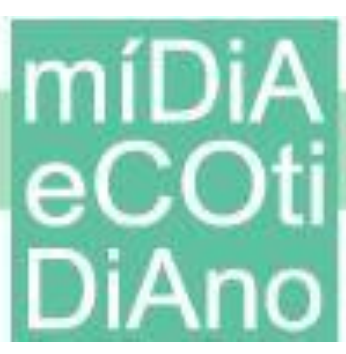

Em Burch (1992, p. 30-31) e seu "Práxis do Cinema", assim como em "O olhar e a cena", de Ismail Xavier (2003, p. 40), recai sobre o movimento dos olhos do ator parte da missão de conduzir a atenção do espectador. Um ator que desvia sua atenção de um ponto e monta novos traços faciais para lançar seu olhar em direção a algo que não é verificável no mesmo quadro endereça, junto à montagem, um novo assunto para além do que se pode constatar, plano que chegará com um horizonte de expectativa já armado. Sustentando um determinado ritmo na esfera da apreciação, essa técnica de manutenção da atenção concatena vetores sonoros e visuais de lá para cá, podendo até mesclar novas diegeses no decorrer do filme, como provocava o realizador e artista visual brasileiro Arthur Omar.

Xavier (2003, p. 35) nos orienta, no mesmo compasso que Pudovkin, décadas antes: "Há entre o aparato cinematográfico e o olho natural uma série de elementos e operações comuns que favorecem uma identificação do meu olhar com o da câmera, resultando daí um forte sentimento da presença do mundo emoldurado na tela...". O russo afirmava:

No exemplo do observador que aprecia a passeata na rua, aprendemos que o processo de filmagem não é a fixação pura e simples do que acontece na frente da câmera, mas sim uma forma peculiar de representação deste fato. Entre o evento natural e sua aparência na tela há uma diferença bem marcada. É exatamente esta diferença que faz do cinema uma arte (PUDOVKIN, 1983, p. 68).

É também precisamente essa diferença que sublima diversas maneiras de ver, criando mundos em detrimento de outros, escolhendo ignorar ou lidar com atenções flutuantes, dispersões criativas e desconexões estranhamente belas, espalhando-se em artes e em regimes visuais que não se desentranham da vida dos dias. A produção cinematográfica ficcional da indústria cerca os atos de olhar. Não se trata de fatalismo ou desilusão, mas de entender criticamente que as narrativas audiovisuais de grande impacto comercial devem, por definição, atender a propósitos que não condizem com o sobrevoo e a alegria de uma atenção que falta. 


\section{Cinema para falar: relatos de pesquisa}

Faremos o relato sobre encontros que ocorreram em dois momentos e dois contextos distintos, nas duas etapas iniciais da pesquisa: o primeiro ocorreu em uma unidade socioeducativa de Fortaleza/CE (2015 e 2016) e o segundo com adolescentes em regime de liberdade assistida e prestação de serviço à comunidade em um centro cultural de Belo Horizonte/MG (2018). Neste artigo, não apresentaremos tanto as falas, estamos mais concentrados na atuação do dispositivo.

A etapa da pesquisa realizada em Fortaleza teve um caráter exploratório e aconteceu em uma unidade do sistema socioeducativo da cidade ${ }^{9}$, incluindo a projeção de filmes cearenses e outros filmes que estão fora do circuito convencional de exibição, feitos a partir de uma produção mais rústica e de um menor compromisso com exigências técnicas e expressivas que desejam encontrar eco em maiores bilheterias. A fim de promover um contato menos estável com as adolescentes, as obras escolhidas apresentam desafios para a apreciação estética de sua audiência, sendo também instigantes e mais plurais no modo de abordar seu tema. As atividades ${ }^{10}$ no Centro Educacional Aldaci Barbosa inspiraram-se nos trabalhos de Bergala (2008), Migliorin (2015) e Fresquet (2013), realizados em escolas: cinema como lugar da fruição; cinema com câmera como lugar da prática criativa, promovendo novas formas de lidar com o outro a partir de um saber cinematográfico adquirido pelas marcas do fazer cinema.

$\mathrm{Na}$ primeira ocasião, em julho de 2015, exibimos e discutimos nas oportunidades produções cearenses como Selos (Gracielly Dias, 2010), Além da Rua (Natália Viana, 2010), Mauro em Caiena (Leonardo Mouramateus, 2012) e uma pernambucana chamada A onda traz, o vento leva (Gabriel Mascaro, 2012). Somada a

\footnotetext{
${ }^{9} \mathrm{O}$ centro foi o único ao qual tivemos acesso, autorizado por Luciano Tonet, promotor de justiça da infância e da juventude. A unidade foi indicada por Tonet por ser uma das instituições que é referência para as demais devido ao bom trabalho desenvolvido e devido à sua harmonia interna. Neste ponto, surge-nos a inevitável questão de como seria realizar nossa pesquisa nos locais onde a violência está mais presente, onde os motins são constantes e a repressão é a regra: não estaria justamente aí a necessidade de mais atenção e de novas formas de promover maneiras de ver transformadoras? A pergunta parece acolher o risco como forma de trabalho.

${ }^{10}$ Em busca da definição de dinâmicas de ativação prévias, o projeto de extensão Arte, Cultura e Direitos Humanos nas Medidas Socioeducativas em São Carlos, pesquisa do professor Gabriel de Santis Feltran, aparece como uma importante referência, indicando a existência de três momentos: escuta individual, oficina semanal e roda de conversa formativa. O projeto em São Carlos atende adolescentes cumprindo medidas socioeducativas de "Liberdade Assistida" e "Prestação de Serviços à Comunidade".
} 


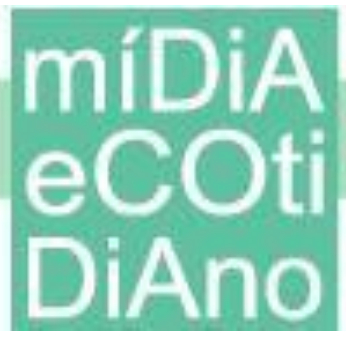

estes filmes, exibimos uma versão modificada pela desaceleração da imagem de um fragmento do filme Bairro 13 (Pierre Morel, 2004), unindo-o à música Sleepwalker (Massive Attack), originalmente parte da banda sonora do filme Ela (Spike Jonze, 2013), como atividade pedagógica de caráter experimental. O grupo, composto por dezoito garotas com idade entre 12 e 18 anos incompletos, conhecia-se pouco, verificamos após algumas perguntas. Algumas das meninas estavam lá havia três dias, enquanto outras, há semanas. Elas comentaram trechos do filme a partir de referências e vivências pessoais, após assistirem à projeção com bastante atenção, momento de envolvimento e alegria. $\mathrm{O}$ planejamento inicial, que previa 5 encontros, não pode ser seguido rigorosamente, porque nossas visitas ficavam sujeitas às dinâmicas das atividades já realizadas no centro, que mudavam de dia e horário com frequência.

Dos dezesseis escritos do grupo de 2016, na primeira ocasião do ano, dois deles chamaram particularmente atenção e por isso gostaríamos de apresentá-los. Os textos não se concentram na descrição dos acontecimentos vistos e não demonstram vontade de estar de acordo com o objetivo daquele que solicita a escrita - tal como requereria a "pedagogia embrutecedora" de que fala Rancière (2012, p. 18), especulamos. Os dois textos partem de impressões mais longe da formatação de uma redação narrativa convencional e mais próximas de um comentário pessoal, o que para nós é um movimento mais revelador. Lêlos traz a certeza de que há ali algo que a pesquisa deve investigar mais a fundo. Observar ambos, diretamente, torna-se importante, sobretudo quando tentamos reproduzi-los tal e qual ocuparam a página - na medida em que esta formatação permite:

Eu gostei muito do filme.

Gostei da parte que ele leva a menina para a praia. i brinca com ela porque ele demonstrou que ele cuida i ama a pequena muito, Bom eu acho que era filha dele por que conta sobre Humildade, carinho, Sofrimento. nunca tinha asistido nada igual, gostei muito,

AMEI ESSE FILMI (Gabriela, 15 anos).

eu gostei de todas as partes eu achei o Personagem humilde, legal, simpatico etc... Gostei não tenho o que reclamar!! Voulte Sempre! Um pouco simples mais foi bom Gostei de Assistir! (Eduarda, 16 anos). 


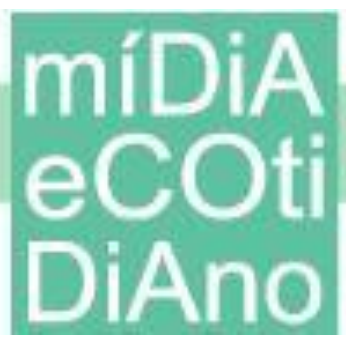

Ficamos especialmente animados com aquilo que poderia também ser tratado como demérito: "um pouco simples mais foi bom". O filme agradece o sincero elogio, antes de tudo. Apesar de simples, ainda assim ser bom, é certamente uma vitória. No dia em que foi exibido A onda traz, o vento leva (Gabriel Mascaro, 2012), cinco dos escritos deram ênfase à surdez, a um diálogo no qual um médico declarava que o personagem era soropositivo e à descrição do encadeamento narrativo. Os dois que expomos exibem algo que, podemos projetar, escapam à imanência do filme, mesmo que escapem de maneira afim, de modo a carregar consigo a possibilidade de uma conversa conciliadora de percepções das duas meninas enquanto escreviam. Nas palavras da folha em branco, um valioso desapego de uma tendência explicativa nos dois escritos - que não buscavam o acerto ou a demonstração da capacidade de síntese, domínio da redação ou exposição do frescor da memória - caiu em cheio em uma espécie de conversa escrita, algo que aponta para nós um trajeto mais instigante. As palavras das adolescentes oferecem grande expectativa quanto à capacidade da presença do cinema nesses espaços de privação da liberdade. Entender a construção da imagem cinematográfica "simples" e "boa" aliada ao indagamento sobre os próprios olhares, gestos e outros movimentos trabalha a percepção sensível e solicita revisões, trazendo uma criticidade que não se separa do corpo em atuação.

O momento de projeção de A onda traz, o vento leva (Gabriel Mascaro, 2012) e $O$ pão e o beco (Abbas Kiarostami, 1970) foi muito agitado. Elas comentaram em voz alta umas com as outras a todo o momento o que estava na tela, fazendo apostas sobre a situação em que se encontrava o personagem em ambos os filmes. Uma conversa sobre as imagens aconteceu espontaneamente, acompanhada de perguntas sobre o que viria a seguir ou sobre dúvidas que surgiram no meio do caminho. O fato de este grupo já se conhecer influenciou diretamente no modo como elas apreciaram o filme, visto que as internas não pararam de interagir, criando um clima semelhante a uma sala de televisão doméstica, situação em que a dispersão é considerável. Após ver A onda traz o vento leva (Gabriel Mascaro, 2012), uma das garotas definiu o personagem principal, qualificandoo como "feliz apesar dos problemas (ser surdo e portador de HIV)". Curioso, indaguei quem tinha feito isso, quem o tinha o definido assim, ao que a adolescente respondeu "ele mesmo" e "deus". 


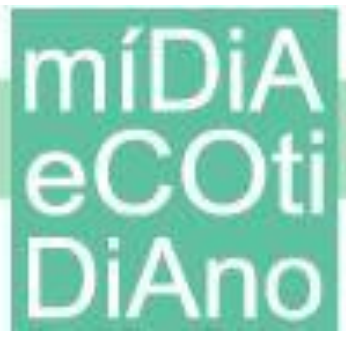

Em meio à projeção de O pão e o beco (Abbas Kiarostami, 1970), entre risos, comentários e perguntas, uma garota perguntou: "Esse filme não tem voz?". A ausência de diálogos no filme não gerou desconforto, mas gerou curiosidade. $\mathrm{O}$ fato de o filme não apresentar falas pareceu não incomodar, mas produziu uma pergunta, que buscamos desdobrar, perguntando sobre o motivo pelo qual o filme nos mantém atentos. Mais um pouco e veio a declaração de outra menina, dizendo que "a gente acompanha os gestos". Há uma dificuldade bastante evidente nesse momento: manter as adolescentes interessadas na discussão sobre o filme. Não se trata de evitar brincadeiras, comentários e perguntas, mas de acolher as interferências mesmo, talvez aceitando que a conversa e a discussão possam acontecer durante a exibição do filme, tornando-se descartável, talvez, a pausa, a concentração e o silêncio que dariam uma autorização para a fala e organizariam a escuta conjunta.

Em um dos encontros, a presença dos educadores, oito no total, igualava-se ao número de internas. $\mathrm{O}$ fato de haver adultos em sala, por vezes tentando conduzir o pensamento das adolescentes sobre o filme para o que achavam ser "o correto", acabou influenciando a experiência, já que a relação com o momento da exibição se daria de outra forma na ausência dessa condução, imaginamos.

Na segunda ocasião, setembro de 2016, encontramos um grupo pequeno, de oito garotas, muito inflamado, cheio de energia e com um comportamento notadamente impaciente. Nada mais comum entre adolescentes que são alunas. A empatia foi outra, e o desejo de cinema, quase por unanimidade, também foi. Impressionou-nos a insistência para assistirmos juntos a Cinquenta tons de cinza (Sam Taylor-Wood, 2015). Afinal, se isso era algum sintoma, como saber de onde e para onde ir então? Com dificuldades operacionais, exibimos Hukkle (György Pálfi, 2002), que provocou mais irritação do que se tivéssemos mostrado Sleep (Andy Warhol, 1963) ou Mothlight (Stan Brakhage, 1963). Interpretamos que a impaciência não era resultado do filme em si, mas de uma dada situação de sala que se dava. A boa acolhida do primeiro grupo contrastava profundamente com a rejeição do segundo, que continha menos da metade de suas integrantes.

As jovens aqui tiveram um momento unicamente reservado para sua fala. $\mathrm{O}$ momento só se completava no instante em que suas falas tomassem o ar. Mas o cinema foi decisivo para isso. Jogar algo da dimensão da fantasia, do sonho, da brincadeira, da 


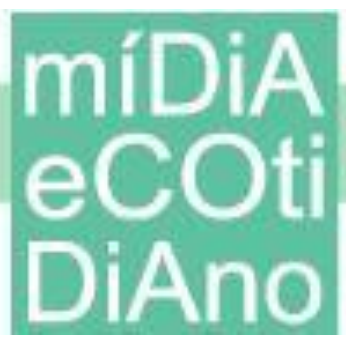

projeção subjetiva no espaço da prisão foi fazer ganhar a história da tela sobre as outras. O cinema na prisão, quando existe, não é mais que uma tela pequena numa sala com arcondicionado e cadeiras escolares. Gostaríamos que não fosse somente isso, mas muitas vezes é um alento. Talvez tenha sido esse momento favorecido uma amizade entre as adolescentes, o técnico e o segurança que as acompanha e eu, como facilitador e educador. Ainda que nem todas falassem, assim se constituiu o espaço para tanto, breve, emotivo e dignificante. Atribuímos, mas do que aos filmes em si, ao ritual cinema - de estar juntos para ver juntos e aproveitar juntos uma história no escuro - o fazer da fala dessas garotas.

Já na experiência de Belo Horizonte, tentamos, inicialmente, trabalhar com um grupo estável de 15 adolescentes. Por meio do agenciamento de gestores do Centro Cultural Venda Nova que oferta atividades culturais válidas no cumprimento de medidas socioeducativas, o Centro de Referência Especializada de Assistência Social (CREAS$\mathrm{VN}$ ) e as analistas de políticas públicas convidaram, no atendimento, os jovens para participar da atividade, que foi nomeada, em sua forma de oficina, "Saberes de Cinema". Assim, o trabalho de campo quase tomava, por empréstimo e por se obrigar a cair nas malhas da institucionalidade do sistema, o corpo de uma medida socioeducativa. De todos os chamados, compareceram onze, sendo sete mais presentes, número que, segundo as profissionais analistas, era muito bom.

As ações se constituíram de ciclos de quatro dias, ocorrendo duas vezes por semana durante três meses. Ao final do quarto dia do processo, um novo ciclo recomeçava. No primeiro dia, prática do futebol. No segundo dia, exibição de um filme sugerido pelos adolescentes. No terceiro dia, exibição de um filme sugerido pela pesquisa. No quarto dia, remontagem coletiva dos materiais que foram assistidos. Todos os encontros foram sucedidos por um momento de roda de conversa, seguida, em algumas ocasiões, de escuta individual.

Os filmes sugeridos pela pesquisa foram reunidos em dois grupos: a um deles, para efeitos didáticos, demos o título de "incitações do tema", no qual estão os documentários de longa-metragem Juízo (Maria Augusta Ramos, 2007) e Pássaro Preto (Maria Pereira, 2016, RJ), e os curtas-metragens A mão e a luva (Roberto Orazi, 2010, PE), Rap, o canto da ceilândia (Adirley Queirós, 2005, DF) e Filme-carta de Recife para Aracaju (Estudantes da Escola Carlos Alberto Gonçalves de Almeida/Case Santa Luzia, 


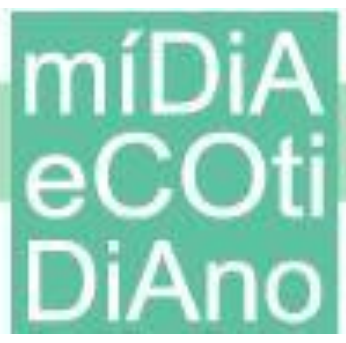

2014). No segundo grupo, que recebeu o nome de "incitações da forma", estão o longametragem de ficção A vizinhança do tigre (Affonso Uchoa, 2014, MG) e os curtas Da janela do meu quarto (Cao Guimarães, 2004, MG), Clave dos Pregões (Pablo Nóbrega, 2015, PE), Sábado à noite (Ivo Lopes Araújo, 2007, CE) e Fantasmas (André Novais Oliveira, 2010, MG). De maneira indisciplinada e intuitiva, fruto da ação progressiva e continuada, não resistimos à tentação de acrescentar, com a atividade em andamento, os filmes $O$ clube dos cinco (John Hughes, 1985), O fim (Peleshian, 1991), Fantasma (Jovens Frequentadores do CAPUT, 2015), Mauro em Caiena (Leonardo Mouramateus, 2012) e Capitães de Areia (Cecilia Amado, 2011). Os filmes sugeridos pelos adolescentes foram todos exibidos: Mac e Devin vão para a escola (Dylan C. Brown, 2012), Ônibus 174 (José Padilha, 2002), Cidade de Deus (Fernando Meireles e Kátia Lund, 2002), Cidade dos Homens (Paulo Morelli, 2007) e Operação Valquíria (Bryan Singer, 2008). Na visão mais geral de todo o desenrolar da atividade, o primeiro dia dos ciclos, destinado a uma roda de conversa seguida de futebol, tornou-se também um momento que acolhia as sugestões de filmes para o segundo dia, reapresentava os princípios da pesquisa e da atividade, esclarecia sobre o andamento das formulações sobre o problema de pesquisa e convocava os adolescentes a participarem com suas elaborações, na forma em que viessem. A primeira rodada de sugestões deles, ouvidas também no primeiro dia das atividades, espontaneamente giraram em torno do mundo do crime, tais como Mac e Devin vão para a escola (Dylan C. Brown, 2012), Conexão Jamaica (Cess Silveira, 2002), Cidade de Deus (Fernando Meireles e Katia Lund, 2002) e Ônibus 174 (José Padilha, 2002).

Ainda que inteiramente planejado, o quarto dia, destinado à remontagem dos materiais, era sempre muito aberto, desejava deixar-se levar pelas interferências. Diferentemente dos outros dias do ciclo, o curso do encontro dependia inteiramente do interesse dos adolescentes em mexer nas imagens e sons. Havia um roteiro para o dia, que impulsionava os primeiros gestos, mas era necessário engajamento por parte dos adolescentes para que a atividade se movesse e fosse ganhando forma. Mudanças vieram com o período de 04 a 26 de setembro/2018. A câmera foi introduzida, mas não foi aceita completamente. Brincar de câmera foi o que conseguimos com os meninos, sem fazer exercícios organizados e sem a necessária frequência deles nos encontros. Mais do que a 


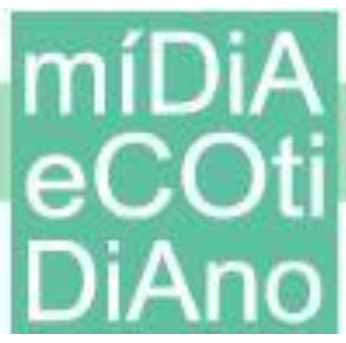

brincadeira com a câmera, que atraiu particularmente três adolescentes, foi exitoso mostrar imagens deles na projeção para falar de cinema. Como não estava prevista uma atividade claramente direcionada ao uso da câmera, sua introdução mais ou menos solta ficou entre um momento puramente de lazer e uma exploração experimental. Assim, os encontros do quarto dia foram passando da remontagem de materiais ao trabalho com conceitos cinematográficos.

Nessa experiência, o estudo centrou-se fundamentalmente nos saberes da experiência de adolescentes, saberes abertos pela oferta de filmes e que pudessem colaborar para a teorização acadêmica, sobretudo no campo das imagens. Durante a experiência fílmica, houve indiferença, deboche, irritação, desagrado, satisfação e envolvimento. A impossibilidade de reter a aparição dessas mais variadas e legítimas dimensões dos participantes espectadores não nos impediu de realizar um exercício de categorização. Nesse esforço preliminar de sistematizar a visionagem dos filmes e a atividade de uma maneira geral, tivemos como norte, portanto, a construção de um saber da experiência, enfrentando um percurso de co-produção nessa elaboração um caminho gradativo: da recusa, passando pela negociação, até chegar à porosidade.

Enquanto recusa, houve com evidência sobre a relação amorosa entre dois homens, com momentos que devem ser destacados. Na exibição de Filme de rua (2017), enquanto as imagens mostravam dois jovens negros dando breves relatos, um adolescente debochou de ambos pelo fato de serem "pretos e ainda bichas", sentindo-se incomodado com as pessoas que falavam na tela. Houve uma negação total, por parte do participante D. C., da homoafetividade. Explicitar o pensamento dessa maneira se parece com defender uma ideia que evidentemente é correta, que definitivamente não se questiona, porque é óbvia. O preconceito nem é cogitado: a regra é homem com mulher. Heteronormatividade seguida como a uma indiscutível natureza humana.

Também é importante tocar em um momento quando assistíamos ao filme Alma no olho (1973), de Zózimo Bulbul. O filme escandalizou a sala por sua ênfase performática, por ser explícito e carnal. O plano detalhe que expandiu a figura das nádegas de Zózimo e as exibiu foi o estopim para as reclamações que já se anunciavam. Em voz alta, todos se agitaram unidos para atacar o que viam: naquela que parecia a 


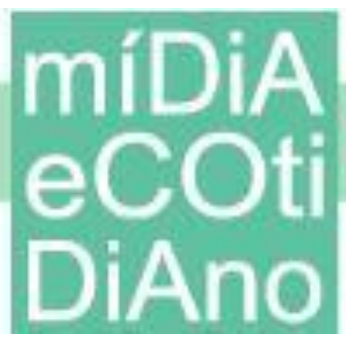

instalação relâmpago de uma pornografia política, não houve qualquer possibilidade de olhar; menos ainda de haver diálogo.

Como negociação, a questão foi o racismo. A pele negra foi uma questão que ocupou alguns dos momentos que avaliei como perturbadores. Na roda de conversa após Alma no olho (1973), ao tentar comentar com os adolescentes sobre a importância de haver um filme que tem um olhar tão detido, explícito e que ressalta os detalhes de um corpo negro, fui rebatido com firmeza. O que eu dizia era absurdo, "não tem a menor necessidade, porque somos todos iguais", disse L. N., negro. C., branco, atacou o filme e a minha defesa, dizendo que era até pior mostrar o filme e falar sobre isso, porque provocava um constrangimento. Na visão dele, isso não era algo para ser falado ali, muito menos em um grupo cuja maioria era composta por pessoas negras, pois era quase uma ofensa.

Para tratar da porosidade, recorremos a Clave dos pregões (2015), de Paulo Nóbrega, que foi elogiado pela turma na roda de conversa e também por R. e A. nas escutas individuais, algo que me surpreendeu bastante. Durante a projeção, silêncio total foi doado ao filme. Mesmo o atípico trabalho sonoro e os planos mais ralentados sem diálogo não provocaram rejeição. O protagonismo que o filme oferece aos vendedores na execução de sua tarefa mais elementar, no cantar do seu negócio que se espalha pelo espaço urbano recifense, repartiu pela imagem um mesmo segmento vivenciado de cidade e de luta. Houve interesse no canto de dois dos trabalhadores mais simples por ruas da cidade e houve cumplicidade. R., na escuta individual, afirmou que esse tinha sido o filme mais legal do dia, em que foram exibidos também Rap, o canto da Ceilândia (2005), A mão e a luva (2013) e O fim (1992). Na ocasião, o jovem preferiu as imagens dos trabalhadores:

Dos quatro, o mais legalzim foi o do vendedor. Eles trabalhando e tudo. Eles fazendo o que pode, né, pra ganhar um dinheiro, cuidar da família. Aqui acontece muito isso também, os caras vendendo picolé aí na rua. Se for olhar, é difícil o cara tá ganhando dinheiro. Conheço muita gente que vende picolé lá perto de casa, anda pra um tanto de lugar. Chega e não vende muito... trabalhadores. Lutando pra conseguir o pouco (R.).

Não houve, na declaração de R. ou durante a roda de conversa com os outros dentro dessa sessão, referência direta a um aspecto propriamente fílmico. Contudo, a 


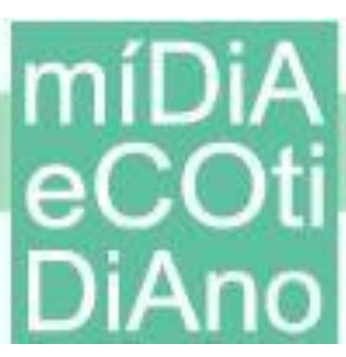

"suavidade" - como eles mesmos dizem - com que aquela construção cinematográfica se apresentou foi tentadora.

Como dissemos, foram sete os adolescentes mais assíduos. Eles tiveram no centro cultural bastante tempo para falar ou quem sabe ainda faltou bastante tempo, comparado ao tanto que calaram. Isso possui uma conexão direta com o tipo de fala que vinha de praticamente todos eles. Ainda que a fala em grupo fosse um tanto quanto tímida, o comentário não se segurava quando se tratava de algo indignante: o sujeito torna-se vilão e é assassinado, a juíza maltrata o réu etc. No entanto, eles falaram durante a sessão, depois da sessão, durante o futebol, durante o lanche. Calaram, desconfiaram, estavam dentro de um sistema que os condenou, da mesma família daquele os intimida diariamente: seus avós, sua mãe e quase que seguramente seus filhos. Seria prudente falar aqui? A fala tanto é favorecida quanto pode ser ofendida. Os filmes, muitos deles ultrapassando qualquer barreira de classe, cor, região e linguagem, expressavam-se como eles e isso os levou a não segurar a própria língua. Aliado a isso, a consciência de que, por mais que estivessem dentro do sistema socioeducativo, era a possibilidade de vencer essa etapa tendo como companheiros filmes e conversas.

\section{Considerações Finais}

O que estaria pressupondo a ideia de socioeducar e como o cinema interfere nisso? Que sociedade e que contexto de vida poderiam estar implícitos na tentativa de uma socioeducação? Seria possível a passagem de uma socioeducação coerciva a uma educação problematizadora de modo a expandir a contagem dos que têm direito à fala e descortinar novos horizontes de participação na construção do social? Nas visitas que fizemos, em conjunto com os exercícios que estamos elaborando, podemos arriscar que a socioeducação parece não se questionar plenamente sobre a sociedade à qual se "devolve" o indivíduo, pois, nas entrelinhas, é imaginado e requerido um adolescente que esteja, rapidamente, pronto para voltar à liberdade sem que volte a causar problemas ao Estado. Aqui, há uma ideia de sociedade composta por uma superfície plana, geograficamente sem acidentes, na qual a jovem ou o jovem, após alguns ajustes em suas arestas, deveria viver fora do crime. Aparar suas expressões salientes, pontiagudas e seus desvios em 


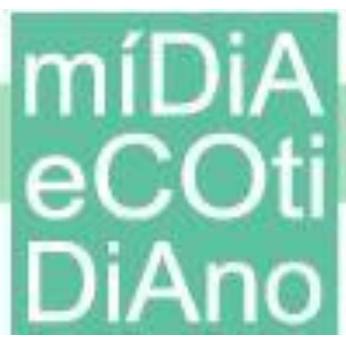

ondas não detectáveis e pouco afins à suposta superfície plana - estável e encaixável - do social não está nos projetos de uma educação estética tal como vislumbramos.

As atividades iniciais de cinema com adolescentes internas indicaram que há muito o que aproveitar desses e de outros encontros, no sentido de diminuir as distâncias e assimetrias sociais a partir de uma revisão de regimes visuais. Chamar a esse processo de educação problematizadora, em vez de replicar intenções de socioeducar - no sentido de coagir/adequar a um social pré-existente, pleno de desigualdades que levam ao próprio "ato infrator" e/ou partir de uma relação de desigualdade para promover igualdade/cidadania - é adotar uma postura de desconfiança ao que está posto como norma geral numa política pública. Isso implica considerar, nos processos educativos e estéticos com as adolescentes em conflito com a lei, os íntimos impasses desses indivíduos com suas aventuras intelectuais e sensíveis em contato com o mundo que os envolve, acolhendo convergências, divergências, entrelaçamentos e contraposições que não necessariamente apontem para sua "recuperação" como a socioeducação os obriga, mas que possam perturbar suas visões de mundo assim como ter o mundo perturbado por suas crenças e atuações, sem que para isso tenham que assumir a criminalidade como modo de afirmação e sobrevivência ou, em outras palavras, como linguagem.

$\mathrm{Na}$ esteira, por um lado, do pensamento de Rancière que faz um diagnóstico crítico da democracia como consenso posto que a igualdade não pode ser pressuposto mas construção permanente, e, de outro lado, do pensamento de Freire que cria um método educacional para quebrar os ciclos de reprodução das desigualdades apostando num saber que habita cada pessoa capaz de fazê-la reconhecer mecanismos de opressão e com isso trabalhar de forma engajada pela permanente e conjunta auto-libertação, podemos concluir que democracia e educação andam de mãos dadas. Não há democracia sem participação, não há participação sem palavra, não há palavra sem linguagem.. Sabereslampejo, diria Didi-Huberman (2011b), frente às duras estruturas do mercado e do Estado que muitas vezes massacram diferenças como holofotes sobre vaga-lumes e produzem um único modo de subjetivação possível e reconhecível como correto e normal. São críticos, portanto, à estabilidade do democrático, apostam numa igualdade que vem. Não há milagres ou paraísos, mas um trabalho de co-criação do comum aberto no qual a estética e o sensível jogam papel fundamental. 
Partir dos princípios da educação problematizadora com base em geradores sensíveis é incluir, por meio de exercícios do olhar e - por meio deles - do agir, o mundo social imperfeito, pontiagudo, flamejante, desproporcional e contingente na própria atividade do sistema socioeducativo. Também é não separar o pensamento sobre socialização de pensar a formação do indivíduo. Implementar ações de cinema dentro dos centros, assumindo que as criações-formações de si e de exercícios cinematográficos estão a se construir, é convidar, nas diversas instâncias institucionais, o risco de encontrar afinidades entre forças da arte, da política e do injusto.

\section{Referências}

ANDREW, J. Dudley. As principais teorias do cinema - uma introdução. Rio de Janeiro: Jorge Zahar Editora, 1989.

BALÁZS, Béla. Nós estamos no filme. In: XAVIER, Ismael (Org.). A Experiência do Cinema. RJ, Graal, 1983.

BALÁZS, Béla. O homem visível. In: XAVIER, Ismael (Org.). A Experiência do Cinema. RJ, Graal, 1983.

BERGALA, Alain. A hipótese-cinema: pequeno tratado de transmissão do cinema dentro e fora da escola. Trad. Mônica Costa Netto, Silvia Pimenta. Rio de Janeiro: Booklink, CINEADLISE-FE/ UFRJ, 2008. Resenha de: LEITE, Gisela Pascale de Camargo; RODRIGUES, Marina.

BURCH, Noël. Práxis do cinema. São Paulo: Perspectiva, 1992.

DIDI-HUBERMAN, Georges. Coisa Pública, Coisa dos povos, Coisa Plural. In: SILVA, Rodrigo; NAZARÉ, Leonor (org.). A república por vir. Arte, Política e Pensamento para o século XXI. Lisboa: Fundação Calouste Gulbenkian, 2011a.

DIDI-HUBERMAN, Georges. Sobrevivência dos vaga-lumes. Trad. Vera Casa Nova e Márcia Arbex, Belo Horizonte: Editora UFMG, 2011b.

FREIRE, Paulo. Pedagogia da esperança: um reencontro com a pedagogia do oprimido. 15. ed. Rio de Janeiro: Paz \& Terra. 2008.

FREIRE, Paulo. Pedagogia do oprimido. 36. ed. Rio de Janeiro: Paz \& Terra, 2003.

FRESQUET, Adriana Mabel. Cinema e Educação: reflexões e experiências com professores e estudantes de educação básica, dentro e "fora" da escola. 1. ed. Belo Horizonte: Autêntica, 2013.

HOOKS, Bell. A construção de uma comunidade pedagógica: um diálogo. In: Ensinando a transgredir: a educação como prática de liberdade. São Paulo: Editora WMF Martins Fontes, 2013.

JULIÃO, Elionaldo Fernandes. Uma visão socioeducativa da educação como programa de reinserção social na política de execução penal. Disponível em: 
<http://www.ufsj.edu.br/portal2-repositorio/File/vertentes/Vertentes_35/elionaldo.pdf >. Acesso em 21 mai. 2015.

LEWIS, Tyson E. The aesthetics of education: theather, curiosity, and politics in the work of Jacques Rancière and Paulo Freire. New York: Bloomsbury, 2012.

MENICUCCI, Clarissa Gonçalves; CARNEIRO, Carla Bronzo Ladeira. Entre monstros e vítimas: a coerção e a socialização no Sistema Socioeducativo de Minas Gerais. Serviço Social e Sociedade. São Paulo, n. 107, p. 535-556, 2011.

MIGLIORIN, Cezar. Inevitavelmente Cinema: educação, política e mafuá. 1. ed. Rio de Janeiro, Beco do Azougue, 2015.

PUDOVKIN, Vsevolod. Métodos de tratamento do material (montagem estrutural). In: XAVIER, Ismail (Org.). A experiência do cinema. São Paulo: Graal, 1983.

RANCIÈRE, Jacques. O desentendimento: Política e Filosofia. Trad. Ângela Leite Lopes. São Paulo: Ed. 34, 1996.

RANCIÈRE, Jacques. O espectador emancipado. São Paulo: Martins Fontes, 2014.

RANCIÈRE, Jacques. O mestre ignorante: cinco lições sobre a emancipação intelectual. Belo Horizonte, Autêntica, 2002.

SILVA, Rodrigo. Apresentação (elegia do comum). In: A república por vir: Arte, política e pensamento para o Século XXI. Lisboa: Calouste Gulbenkian, 2011. p. 11-37.

XAVIER, Ismail. O olhar e a cena. São Paulo: Cosac \& Naify, 2003. 